\title{
Biochemical basis for the toxic effects of triethyl lead
}

\author{
L. GALZIGNA ${ }^{1}$, M. V. FERRARO, G. MANANI, and A. VIOLA \\ Institute of Biological Chemistry, Institute of Industrial Medicine and Institute of \\ Anaesthesiology. University of Padova, 35100 Padova, Italy
}

\begin{abstract}
Galzigna, L., Ferraro, M. V., Manani, G., and Viola, A. (1973). British Journal of Industrial Medicine, 30, 129-133. Biochemical basis for the toxic effects of triethyl lead. The effects of triethyl lead $\left(\mathrm{PbEt}_{3}\right)$ have been studied in vitro on the cholinesterase activity of rat diaphragm and in vivo on serum cholinesterase in the dog. $\mathrm{PbEt}_{3}$ dramatically increases the duration of succinylcholine-induced myoneural block and pyridine-2-aldoxime methiodide (PAM) is able to counteract both cholinesterase inhibition and the effects on neuromuscular transmission. On the other hand, $\mathrm{PbEt}_{3}$ catalyses the rearrangement of catecholamines to aminochromes in vitro and inhibits catecholamine effect on smooth muscle contraction. The toxicity of $\mathrm{PbEt}_{3}$ and particularly its action on the central nervous system can be explained by a combination of effects which might result from an upset of cholinergic and adrenergic central pathways due to the formation of endogenous psychotogenic complexes.
\end{abstract}

In the last few years we have been concerned with the problem of the biochemical basis of the toxicity of alkyl derivatives of lead, particularly by the interference of such compounds with normal metabolic processes.

First we analysed in some detail the effect of tetraethyl lead $\left(\mathrm{PbEt}_{4}\right)$ on the metabolism of the hydroxylated derivatives of tryptophan (Corsi, Galzigna, and Brugnone, 1964). Our results demonstrated that biosynthesis of serotonin is somewhat affected whereas its catabolism is not influenced. Subsequently our attention was focused on the effects of $\mathrm{PbEt}_{4}$ and $\mathrm{PbEt}_{3}$, its active metabolite (Cremer, 1965), on cholinesterase activity. An inhibitory effect of $\mathrm{PbEt}_{3}$ on purified serum cholinesterase was shown in vitro and PAM was able to restore the activity of the inhibited enzyme (Galzigna, Corsi, Saia, and Rizzoli, 1969). These results were questioned on the basis of data showing that no inhibition of blood cholinesterases is observable when a concentration of $\mathrm{PbEt}_{3}$ of the same order as

'Present address: Department of Medical Biochemistry, University of Nairobi, PO Box 30197, Nairobi, Kenya. the toxic dose is used (Chiesura, 1970). We must specify that we did not intend to propose a method for biochemical diagnosis of the intoxication but only to build up a phenomenological model which might account for the toxic effects of $\mathrm{PbEt}_{3}$. We based our assumptions on a localized effect of $\mathrm{PbEt}_{3}$ at the level of the central nervous system (CNS) (Cremer, 1965) in the light of the particular importance of the aspecific cholinesterase of CNS considered as a barrier for the neurotransmitter acetylcholine (Galzigna, 1970). On the other hand, we wish to emphasize that all tissues are a particularly heterogeneous system and the chemical potential of any toxic compound reaches its highest value at the level of specific structures within the tissue so that the concentration in a target area must be much higher than the concentration referred to the whole tissue or the whole body.

In this paper we present further data on the inhibitory effects of $\mathrm{PbEt}_{3}$ on cholinesterase both in vitro and in vivo and on its interference with the mechanisms of the succinylcholine-induced depolarizing block of cholinergic transmission. These data will be discussed together with the effects of 
$\mathrm{PbEt}_{3}$ on adrenergic mechanisms on the basis of our recent studies on the biochemistry of psychotic reactions (Galzigna, 1972).

\section{Materials and methods}

Phrenic-diaphragm preparations obtained from 10 Wistar strain adult male rats were used as a source of crude acetylcholinesterase for the in vitro experiments. The enzymatic activity was detected with acetylthiocholine (Fluka, Buchs) substrate using rat diaphragm homogenates in $0.25 \mathrm{M}$ sucrose as enzyme and dithiobisnitrobenzoic acid (Fluka, Buchs) as a chromogen, according to Ellman, Courtney, Andres, and Featherstone, (1961).

$\mathrm{PbEt}_{3}$ chloride (Sloi, Trento) free from inorganic lead was dissolved in double distilled water and used for both in vitro experiments and intravenous administration to 10 adult male dogs (6-12 $\mathrm{kg}$ body weight). The effect of $\mathrm{PbEt}_{3}(6 \mathrm{mg} / \mathrm{kg})$ was checked on serum cholinesterase activity followed at intervals after its administration. The interference of $\mathrm{PbEt}_{3}$ on a depolarizing myoneural block induced by succinylcholine (Syncurine, Wellcome) was studied by an electromyographic (EMG) technique already described (Galzigna et al., 1972) and the protective action of PAM (Farmitalia, Milan) on both cholinesterase inhibition and neuromuscular function was demonstrated.

The chemical interaction between $\mathrm{PbEt}_{3}$ and norepinephrine (or dopamine) (Calbiochem, Los Angeles) in a dioxane-water system was documented according to the procedure used in the previous studies (Galzigna, 1970; 1972) and the interference of $\mathrm{PbEt}_{3}$ on catecholamine action was assayed with the isolated rabbit ileum technique (Galzigna et al., 1972). Three domestic rabbits were used and the contractile activity of the ileum dipped in 75 $\mathrm{ml}$ of Tyrode's solution was followed with a kymograph at $37^{\circ} \mathrm{C}$.

Further details of the experimental conditions are given in the captions to the figures.

\section{Results}

Figure 1 shows the effect of different concentrations of $\mathrm{PbEt}_{3}$ in vitro on acetylcholinesterase activity of rat diaphragm with two concentrations of substrate acetylthiocholine. The inhibition is non-competitive, as proved by plotting Fig. 1 results as the reciprocal of the velocity of acetylcholine hydrolysis versus the concentration of the inhibitor (Webb, 1966). The highest inhibition obtained corresponds to about $25 \%$ of the normal activity and as we proved (Galzigna et al., 1972) that the usual inhibitors of aspecific (or pseudo-) cholinesterase are able to induce a maximal inhibition of $25-30 \%$ on the true cholinesterase activity of rat diaphragm preparation, it seems that $\mathrm{PbEt}_{3}$ has this characteristic in common with aspecific cholinesterase inhibitors.

An apparent $K_{i}$ value of the order of $10^{-3} \mathrm{M}$ for the crude enzyme, much higher than the value obtained for the purified enzyme (Galzigna et al., 1969), can be calculated.

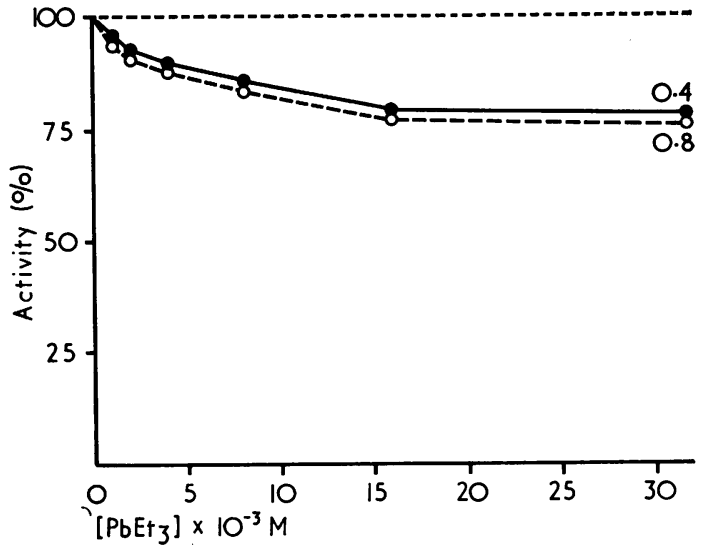

FIG. 1. Inhibitory effect of different concentrations of $\mathrm{PbEt}_{3}$ on acetylcholinesterase activity of rat phrenicdiaphragm homogenates. An activity of 100 corresponds to $0.01 \mu$ Mole of acetylthiocholine hydrolysed per minute per mg of protein of the homogenate. Colorimetric values are obtained with a Beckman DU spectrophotometer at $25^{\circ} \mathrm{C}$ and $412 \mathrm{~nm}$. A calibration curve with $\mathrm{N}$-acetyl-L-cysteine (Erba, Milan) is used. The two levels of $0.26 \mathrm{M}$ acetylthiocholine are 0.4 and $0.8 \mathrm{ml}$ in a final volume of $4 \mathrm{ml}$ of incubation mixture. Each value is an average of 10 experiments.

Figure 2 shows the percent inhibition of serum cholinesterase assayed in blood taken at different times after administration of $\mathrm{PbEt}_{3}$ to dogs. Maximum inhibition is observed 15 minutes and full

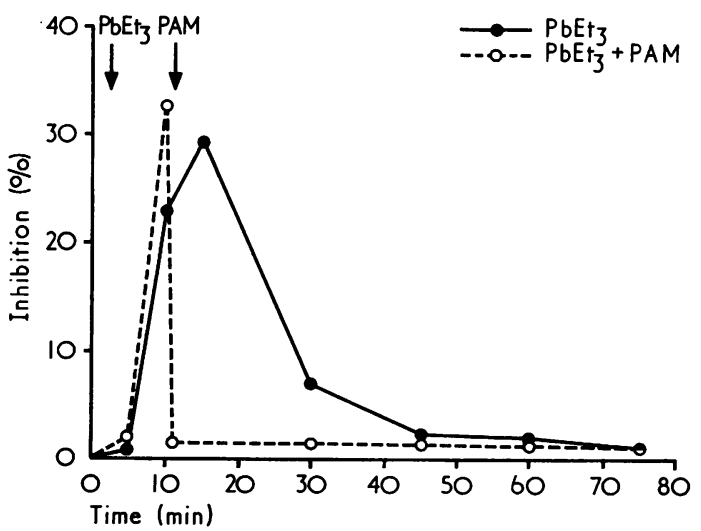

FIG. 2. Inhibition of serum cholinesterase after $\mathrm{PbEt}_{3}$ $(6 \mathrm{mg} / \mathrm{kg})$ given to dogs by fast flowing infusion, and the protective effect of PAM $(36 \mathrm{mg} / \mathrm{kg})$. The values are an average of 10 experiments (5 with $\mathrm{PbEt}_{3}$ alone and 5 with $\mathrm{PbEt}_{3}$ and PAM). A normal activity corresponds to $0.08 \mu$ Moles of acetylthiocholine hydrolysed per minute per $\mathrm{ml}$ of serum. 
recovery 45 minutes after administration. The administration of PAM brings back almost immediately the activity of serum cholinesterase at normal values.
The effect of $\mathrm{PbEt}_{3}$ on a succinylcholine induced depolarizing block is shown in the EMG tracings (Fig. 3). A complete recovery of transmission does not occur until 66 minutes whereas succinylcholine

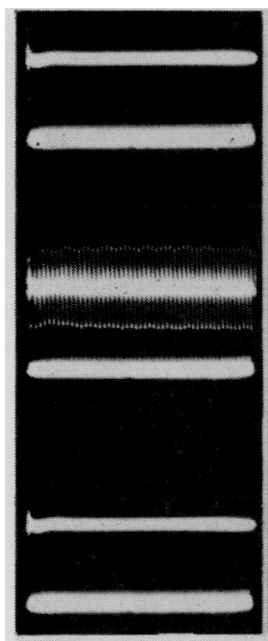

a

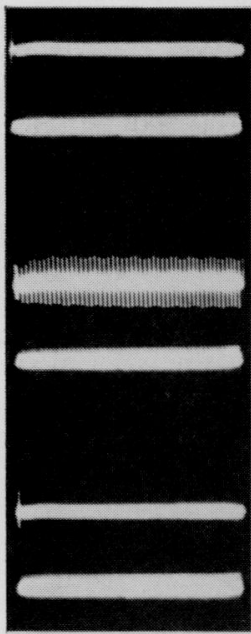

e

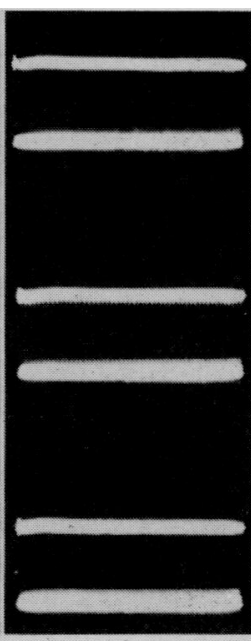

b

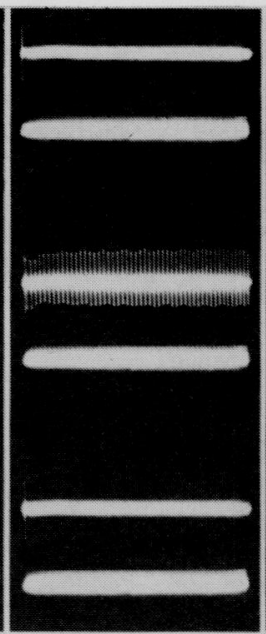

$f$

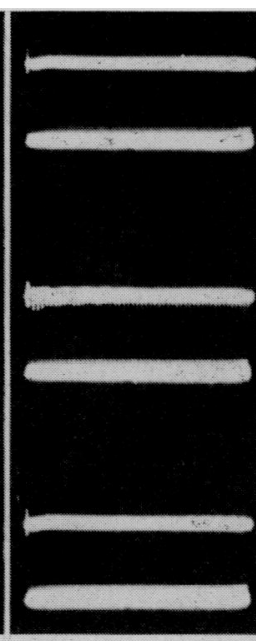

c

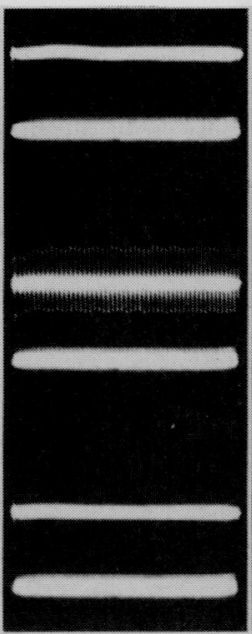

9

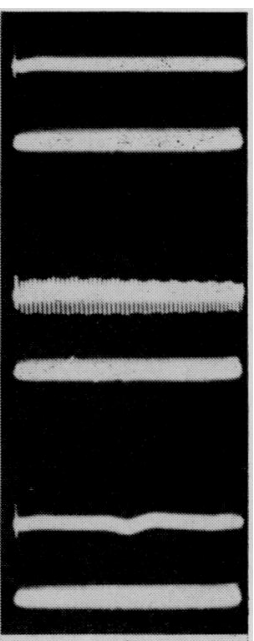

d

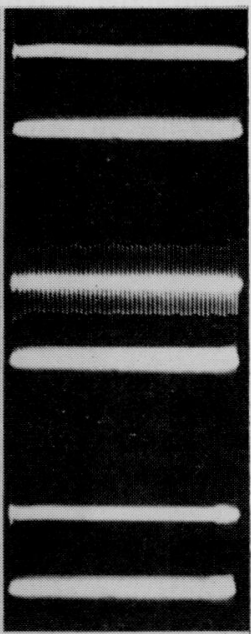

h

FIG. 3. Typical EMG tracing obtained after single-tetanic-single sequences of stimulation. Succinylcholine $(0.05 \mathrm{mg} / \mathrm{kg})$ is given 10 minutes after $\mathrm{PbEt}_{3}(8$ $\mathrm{mg} / \mathrm{kg}$ ). The control (a), showing normal transmission, is followed by a tracing taken 11 minutes after succinylcholine administration $(b)$.

The recovery is slow and gradual and almost normal neurotransmission $(h)$ returns after 66 minutes.

Without $\mathrm{PbEt}_{3}$ the recovery begins 4 minutes after succinylcholine and is complete by 6 minutes. If PAM (36 mg/ $/ \mathrm{kg})$ is given together with succinylcholine 10 minutes after $\mathrm{PbEt}_{3}$ the recovery begins within 2 minutes and is complete by 5 minutes. The EMG changes are in any case typical of a depolarizing block. 
alone, in the same conditions, induces a block lasting only 6 minutes. This is explained by competition between $\mathrm{PbEt}_{3}$ and succinylcholine for serum cholinesterase. The presence of $\mathrm{PbEt}_{3}$ allows a very long duration of succinylcholine action and PAM is able to abolish completely such an effect.

The recording of electroencephalographic activity after $\mathrm{PbEt}_{3}$ was used to monitor the subcortical effects of $\mathrm{PbEt}_{3}$ at the CNS level and a complete discussion of this aspect is given elsewhere (Manani et al., 1972).

Figure 4 shows the absorption spectrum of norepinephrine in a dioxane-tris mixture taken 1 hour after the addition of $\mathrm{PbEt}_{3}$. The typical absorptior peaks of aminochromes are present in the $\mathrm{PbEt}_{3}$ treated sample, demonstrating the catalytic effect of $\mathrm{PbEt}_{3}$ on the cyclization of norepinephrine. Inorganic lead does not induce a similar effect, probably because it is insoluble in the mixture. This has a low dielectric constant and is taken as a model of the physicochemical features of the CNS milieu (Galzigna, 1970).

The ability of $\mathrm{PbEt}_{3}$ to antagonize the effect of norepinephrine in vivo is demonstrated in Fig. 5 in which both the relaxation induced by norepinephrine on rabbit ileum contraction and the recovery of the contractile activity due to $\mathrm{PbEt}_{3}$ are shown. $\mathrm{PbEt}_{3}$ alone at the same concentration was without any effect on normal contractile activity.

\section{Discussion}

The relationship between enzymatic inhibition induced by a compound and its toxic power has been extensively studied (Webb, 1966) and some analytical expressions which quantitatively define such a

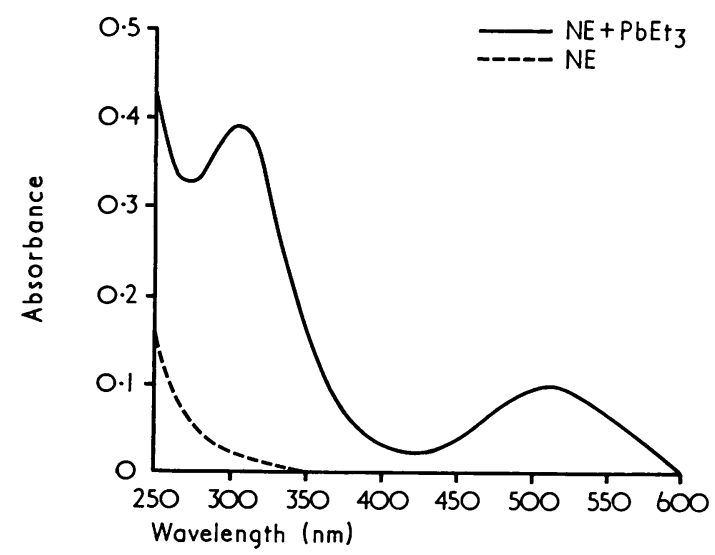

FIG. 4. Absorption spectra of $0.0125 \mathrm{M}$ norepinephrine (NE) dissolved in a mixture $(\mathrm{v} / \mathrm{v})$ of $0.25 \mathrm{M}$ tris- $\mathrm{HCl}$, pH $7 \cdot 8$, and dioxane $(1: 1)$ taken 1 hour after addition of $8.5 \times 10^{-3} \mathrm{M} \mathrm{PbEt}_{3}$.

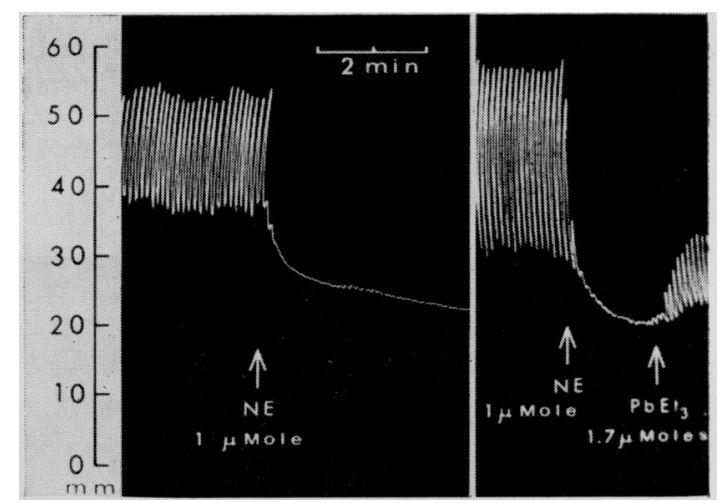

FIG. 5. Recording of rabbit ileum contraction. The tracing shows after normal contractile activity the relaxation by norepinephrine (NE) and the contraction induced by $\mathrm{PbEt}_{\mathbf{3}}$.

relationship have been formulated. We summarize such expressions by the formula:

$$
(I)_{t}=K_{i} / C
$$

where $(I)_{t}$ is the toxic dose of a compound, $K_{i}$ is the constant for the inhibition of an enzymatic reaction induced by the compound, and $C$ is a constant depending on the kinetic constants relative to the deactivation of the compound in vivo.

The most common situation occurs when $C$ is large and therefore $(I)_{t}$ is much lower than $K_{i}$.

The present data are in agreement with our previous results on the inhibition of purified cholinesterase and the reactivating effect of PAM. The EMG results are easily understood in terms of blood cholinesterase inhibition induced by $\mathrm{PbEt}_{3}$ which in this way is able to increase the duration of the succinylcholine dependent neuromuscular block. At CNS level an inhibition of the aspecific cholinesterase may result in a sort of acetylcholine overflow which would be very dangerous if it occurred at the same time as aminochromes formation (Galzigna, 1970).

In fact we have shown that $\mathrm{PbEt}_{3}$ is able to catalyse in vitro the reaction:

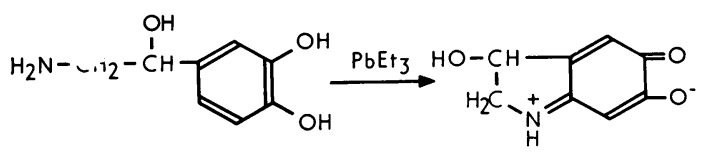

The combined effect of acetylcholine 'leaks' from cholinergic synapses and aminochrome formation might lead to the presence of psychotogenic acetylcholine-aminochrome complexes which have been indicated as the possible biochemical cause for the 
onset of some types of psychotic disturbances (Galzigna, 1970). In fact a true psychotogenic effect of aminochromes has been found only when they are combined with acetylcholine to form molecular complexes (Galzigna and Rizzoli, 1970).

The complexity of the action of alkylated derivatives of lead can be well explained by their multimodal effect on the CNS and particularly by the interference with cholinergic, adrenergic, and serotoninergic processes. We think, however, that the psychotic symptoms which are characteristic of $\mathrm{PbEt}_{4}$ intoxication can be rationalized on the basis of the following scheme:

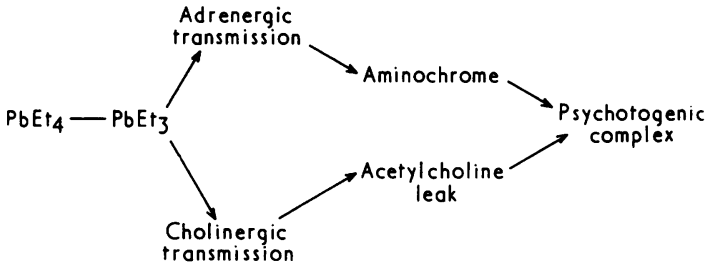

The transformation of $\mathrm{PbEt}_{4}$ into $\mathrm{PbEt}_{3}$ has been shown by Cremer (1965). The toxic action of $\mathrm{PbEt}_{3}$ might be related mainly to a transformation of norepinephrine into an aminochrome which is stabilized by acetylcholine leaking from cholinergic neurones after inhibition of pseudocholinesterase. These combined effects result in the formation of a psychotogenic complex particularly active at the central nervous system level.

The biochemical basis of treatment with chlorpromazine, which has recently been demonstrated as a trapping agent of aminochromes capable of successful competition with acetylcholine (Galzigna, 1972), may now be found. On the other hand, PAM should reactivate the blocked cholinesterase and in such a way stop the possible acetylcholine leaks.

All the present experimental findings await future clinical studies which will allow the proposed model to be either confirmed or rejected.

We wish to thank Professor M. Crepet and A. Gasparetto for their encouragement, and Drs. F. Battocchio and S. Mammano for technical collaboration.

\section{References}

Chiesura, P. (1970). Diagnostic criteria in intoxication from tetraethyl lead $\left(\mathrm{PbEt}_{4}\right)$ with particular reference to forms of moderate seriousness (in Italian). Lavoro umano, 22, 3-19.

Corsi, G. C., Galzigna, L., and Brugnone, F. (1964). Sul metabolismo del triptofano nell' intossicazione sperimentale da piombo tetraetile. Medicina del lavoro, 55, 665-678.

Cremer, J. E. (1965). Toxicology and biochemistry of alkyl lead compounds. Occupational Health Review, 17, No. 3, 14-19 (Ottawa).

Ellman, G. L., Courtney, K. D., Andres, V., and Featherstone, R. M. (1961). A new and rapid colorimetric determination of acetylcholinesterase activity. Biochemical Pharmacology, 7, 88-95.

Galzigna, L. (1970). Complexes between acetylcholine and catecholamines and their tolerance to mental illness. Nature, 225, 1058-1059.

(1972). Interaction of chloropromazine with adrenochrome and interference of a possible endogenous psychotogenic agent with some synaptic enzyme activities. Biochemical Pharmacology, 21, 203-207.

- Corsi, G. C., Saia, B., and Rizzoli, A. A. (1969). Inhibitory effect of triethyl lead on serum cholinesterase in vitro. Clinica chimica acta, 26, 391-393.

-, Manani, G., Mammano, S., Gasparetto, A, and Deana, R. (1972). Experimental study on the neuromuscular blocking action of procaine amide. Agressologie, 13, 107-116.

- , and Rizzoli, A. A. (1970) Short circuit theory on the onset of mental illness. Clinica chimica Acta, 30, 5-11.

Manani, G., Gasparetto, A., Battocchio, F., Negrin, P., and Galzigna, L. (1972). Electromyographic and electroencephalographic studies in acute poisoning by triethyl lead in dog (in Italian). Acta anaesthesiologica, 23, 3-13.

Webb, J. L. (1966). Enzymes and Metabolic Inhibitors, vol. I, pp. 646-648. Academic Press, New York.

Received for publication May 30, 1972.

Accepted for publication August 19, 1972. 